OAJIS

Journal of

Information

Systems

is.its.ac.id/pubs/oajis/

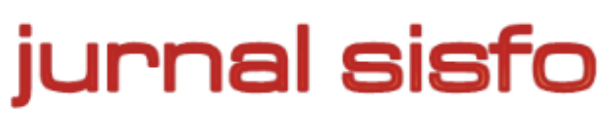

Jurnal Sisfo Vol. 06 No. 01 (2016) 105-120

\title{
Pembuatan Standar Operasional Prosedur (SOP) Manajemen Akses Untuk Aplikasi E-Performance Bina Program Kota Surabaya Berdasarkan Kerangka Kerja ITIL V3 Dan ISO 27002
}

\author{
Wildan Radista Wicaksana, Anisah Herdiyanti*, Tony Dwi Susanto \\ Jurusan Sistem Informasi, Fakultas Teknologi Informasi, Institut Teknologi Sepuluh Nopember
}

\begin{abstract}
Surabaya has been adopting e-government within its administration process. Among those adoptions, one of its unit namely Bina Program Kota Surabaya developed Government Resources Management Systems (GRMS) to support government activities in all government units in Surabaya. The implementation of the system is important and so is the effective use of the system. To be able to ensure the effective use of the system, a standard operating procedure (SOP) is required. This research focuses on the governance-side of the GRMS by developing an SOP for access management to support e-Performance - one of the GRMS applications. E-performance system is complex in nature because it involves a number of users from various users' level application. In order to develop an SOP for access management, gap analysis were conducted by identifying the missing process between existing and expected (ideal) situation for managing access. Following this, step-by-steps to manage access based on the level of access rights were developed within the SOP. All of the six SOPs resulted from this study have been reviewed and simulated within Bina Program. The SOPs for access management has given a standard to manage access rights in order to avoid ambiguities, and further misuse of data and information.
\end{abstract}

Keywords: Standard Operating Procedure, Access Management, GAP Analysis, ITIL V3, ISO 27002

\begin{abstract}
Abstrak
Salah satu diantara aplikasi yang dikembangkah oleh Bagian Bina Program Pemerintah Kota Surabaya adalah aplikasi E-Performance. Aplikasi ini memungkinkan kontrol kinerja individu di masing-masing Satuan Kerja Perangkat Daerah (SKPD). Terlepas dari kompeksitas aplikasi karena melibatkan berbagai level pengguna aplikasi yang berbeda, aplikasi E-Performance belum dilengkapi dengan standar penyelenggaraan proses dalam mengelola level hak akses. Diantara permasalahan yang timbul terjadinya redudansi peran (roles) yang berpotensi penyalahgunaan wewenang. Sebuah prosedur operasional standar (SOP) dapat memastikan perilaku pengguna terhadap sistem sesuai dengan standar yang diacu. Penelitian ini berfokus kepada pembuatan SOP untuk manajemen akses yang dibangun melalui analisis kesenjangan kondisi kekinian dengan kondisi ekspektasi (ideal). Selanjutnya langkah-langkah dalam pengelolaan akses dideskripsikan ke dalam dokumen prosedur dan formulir. Hasil dari penelitian ini berupa 6 (enam) prosedur dan 12 formulir. Dengan adanya dokumen SOP tersebut diharapkan dapat mengontrol penggunaan aplikasi berdasarkan level hak akses yang dimiliki oleh pengguna sekaligus melindungi aset informasi yang bersifat rahasia.
\end{abstract}

Kata kunci: Standar Operasional Prosedur, Manajemen Akses, Analisis Kesenjangan, ITIL V3, ISO 27002

(C) 2016 Jurnal SISFO.

Histori Artikel : Disubmit 15 Juli 2016; Diterima 16 September 2016; Tersedia online 16 September 2016

${ }^{*}$ Corresponding Author

Email address: anisah.herdiyanti@gmail.com (Anisah Herdiyanti) 


\section{Pendahuluan}

Dalam mengoptimalkan kinerja aparatur Pemerintah Kota Surabaya dalam rangka penyelenggaraan Pemerintahan serta memberikan pelayanan kepada masyarakat maka perlu didukung dengan adanya pemanfaatan teknologi informasi dan komunikasi yang memadai [1]. Oleh karenanya, Pemerintah Kota Surabaya mencanangkan penerapan E-Government dalam proses pemerintahan dan mendirikan sebuah fungsi internal dalam pemerintahan, yang dinamakan Bagian Bina Program Kota Surabaya. Dalam mendukung fungsi dan tugasnya, Bagian Bina Program Kota Surabaya membuat sebuah sistem yang dinamakan Government Resources Management Systems (GRMS). Sistem ini terdiri atas enam sistem yang saling terintegrasi, yaitu E-Budgeting, E-Project, E-Procurement, E-Delivery, E-Controlling, dan EPerformance [2]. Saat ini Bina Program telah memiliki sertifikasi ISO 27002:2005 pada aplikasi EProcurement dan berusaha meningkatkan layanan pada sistem-sistem yang lain. Namun di dalam penerapannya, sistem-sistem ini memerlukan sebuah standard operasional prosedur (SOP) yang dapat mengontrol perilaku organisasi terhadap sistem. Salah satu bentuk penerapan SOP dapat digunakan dalam pengelolaan manajemen akses.

Adanya manajemen akses pada aplikasi dapat mengurangi terjadinya penyalahgunaan hak akses oleh pihak tertentu dan penyalahgunaan data dan informasi didalamnya [3]. Selain itu dapat melindungi data dan informasi yang bersifat rahasia dan hanya pihak tertentu saja yang dapat mengaksesnya. Salah satu sistem yang berkaitan dengan kinerja pegawai Pemkot Surabaya dan memerlukan manajemen akses adalah aplikasi E-Performance. E-Performance merupakan sistem informasi manajemen kinerja dalam rangka penilaian prestasi kinerja pegawai yang lebih objektif, terukur, akuntabel, partisipatif dan transparan, sehingga terwujud manajemen pegawai berdasarkan prestasi kerja dan sistem karir kerja Pegawai Negeri Sipil (PNS) di lingkungan Pemerintah Kota Surabaya [4]. Penggunaan aplikasi E-Performance saat ini juga tak luput dari permasalahan. Permasalahan pertama adalah dapat terjadinya penyalahgunaan hak akses oleh beberapa admin SKPD yang memiliki hak akses yang sama. Permasalahan kedua adalah apabila terdapat kesalahan pemberian hak akses maka dapat mempengaruhi penilaian kinerja pegawai dan mempengaruhi tunjangan gaji yang diterima pegawai. Permasalahan ketiga adalah informasi di dalam aplikasi bersifat rentan dan rahasia, sehingga perlu dilakukan pencegahan terkait dengan hak akses. Permasalahan keempat adalah ketidakjelasan proses komunikasi antara admin SKPD dan Super Admin Bina Program perihal manajemen akses.

Keempat permasalahan tersebut harus diatasi karena jumlah SKPD di Kota Surabaya sebanyak 72 unit dan pengguna aplikasi E-Performance sebanyak 7777 orang yang terbagi kedalam 6 level pengguna [5]. Banyaknya level pengguna tersebut menyebabkan kerentanan terhadap keamanan informasi di dalam aplikasi E-Performance. Adapun kerentanan informasi berkaitan dengan 3 aspek keamanan informasi, yaitu Integrity dan Availability [6]. Selain itu manajemen akses pada aplikasi E-Performance akan berpengaruh pula pada pemberian tunjangan kinerja Pegawai Negeri Sipil Daerah (PNSD) Kota Surabaya. Untuk menyelesaikan permasalahan tersebut maka diperlukanlah SOP manajemen akses yang berkaitan dengan pengelolaan hak akses pada aplikasi E-Performance. Dalam pembuatan SOP, digunakanlah metode analisis kesenjangan dengan melihat kondisi kekinian layanan pada Bagian Bina Program terhadap kondisi ekspektasi maupun kondisi ideal sesuai dengan kerangka kerja. Dalam melakukan peyusunan dokumen SOP, digunakan acuan Peraturan Menteri Pendayagunaan Aparatur Negara dan Reformasi Birokrasi Republik Indonesia Nomor 35 Tahun 2012 Tentang Pedoman Penyusunan Standar Operasional Prosedur Administrasi Pemerintahan dalam menyusun kriteria dan format SOP yang ada di dalam dokumen SOP [7]. Pembuatan SOP juga mengacu pada kerangka kerja mengenai manajemen akses yang ada, yaitu proses Access Management ITIL V3 pada tahap service operation dan kontrol akses pada ISO 27002 yang berkaitan dengan keamanan informasi. Penggunaan ISO 27002:2005 didasarkan pada sertifikasi ISO 27002 yang telah diperoleh Bina Program pada aplikasi E-Procurement. Dengan adanya SOP diharapkan dapat meningkatkan layanan pada aplikasi E-Performance Bagian Bina Program Kota Surabaya. 


\section{Tinjauan Pustaka}

\subsection{Aplikasi E-Performance Bina Program Kota Surabaya}

Aplikasi E-Performance adalah salah satu aplikasi dalam Management Government Resources Management Systems (GRMS). Aplikasi E-Performance merupakan sistem informasi manajemen kinerja dalam rangka penilaian prestasi kinerja pegawai yang lebih objektif, terukur, akuntabel, partisipatif dan transparan, sehingga terwujud manajemen pegawai berdasarkan prestasi kerja dan sistem karir kerja Pegawai Negeri Sipil (PNS) di lingkungan Pemerintah Kota Surabaya [4].

Manfaat aplikasi E-Performance antara lain:

1) Tersedianya database Pegawai Negeri Sipil Daerah (PNSD) di Lingkungan Pemerintah Kota Surabaya.

2) Alat untuk melakukan monitor aktivitas Pegawai Negeri Sipil Daerah (PNSD) di Lingkungan Pemerintah Kota Surabaya.

3) Alat untuk mengukur kinerja Pegawai Negeri Sipil Daerah (PNSD) di Lingkungan Pemerintah Kota Surabaya.

\subsection{Standard Operating Procedure}

Menurut Griffin, Standar Operasional Prosedur (SOP) merupakan suatu standar perencanaan yang menguraikan langkah-langkah yang harus dilaksanakan pada keadaan tertentu [8]. SOP merupakan serangkaian panduan yang disusun secara sistematis mengenai proses, tugas, dan peran dari masingmasing individu atau kelompok yang dilakukan sehari-hari dalam suatu organisasi. Dengan adanya SOP maka aktivitas yang dilakukan akan terstandarisasi dan memudahkan dalam transparansi serta akuntabilitas di organisasi. Selain itu adanya SOP juga memberikan arahan kerja berupa konsep yang jelas serta pihak yang bersangkutan.

Beberapa manfaat yang didapatkan dalam penerapan SOP diantaranya:

1) Dapat menstandarkan aktivitas yang dilakukan oleh pihak yang bersangkutan

2) Dapat meningkatkan efisiensi dan efektivitas pelaksanaan tugas dan tanggung jawab oleh pihak yang melaksanakan tugas

3) Dapat mengurangi kesalahan yang mungkin dilakukan dalam melakukan aktivitas

4) Dapat menjelaskan secara detail semua kegiatan dalam suatu proses secara lebih jelas dan terperinci

5) Dapat memudahkan komunikasi antara pihak-pihak terkait

6) Dapat menciptakan ukuran standar kinerja bagi penilaian kinerja pihak yang bersangkutan

7) Dapat memberikan informasi dalam upaya peningkatan kinerja pegawai

\subsection{Access Management}

Access Management merupakan salah satu proses pada ITIL V3 yang terletak dalam tahapan Service Operation. Manajemen akses merupakan proses pengklasifikasian akses pada pengguna layanan dengan memberikan hak akses kepada pengguna yang berhak dan pencegahan pemberian hak akses kepada pengguna yang tidak berhak [3]. Manajemen akses selayaknya sebuah aturan tentang bagaimana sebuah layanan dapat digunakan untuk user tertentu.

Tujuan dari manajemen akses meliputi:

1) Mengelola penggunaan pemberian akses terhadap layanan, data, maupun fungsi tertentu 
2) Mengatur pemberian hak akses kepada pengguna agar pengguna dapat mengakses layana secara efektif dan sesuai dengan hak akses yang diberikan

3) Menghapus akses ketika pengguna berganti pekerjaan atau tanggung jawab

4) Melindungi keamanan informasi dan data yang terdapat dalam layanan TI.

5) Dapat mempermudah ketika melakukan audit layanan TI

\subsection{Klausul ISO/IEC 27002:2005}

Standar ISO/IEC 27002:2005 merupakan standar mengenai keamanan informasi. Standar ini memberikan panduan dalam perencaan dan implementasi suatu program untuk melindung aset-aset informasi, salah satunya adalah data di dalam aplikasi [9]. ISO/IEC 27002 menyediakan rekomendasi best practice terhadap manajemen keamanan informasi yang dapat digunakan dalam proses inisiasi, implementasi, dan pemeliharaan Information Security Management Systems (ISMS) pada suatu organisasi.

\subsection{Analisis Kesenjangan}

Analisis kesenjangan dapat mengidentifikasi proses-proses yang kurang efektif sehingga dapat mengurangi kesenjangan agar tercapainya kondisi yang diharapkan. Tujuan dari analisis kesenjangan adalah untuk mencapai kondisi yang diharapkan oleh organisasi sehingga tujuan dari organisasi dapat tercapai.

\section{Metodologi}

Metodologi penelitian merupakan acuan bagi peneliti dalam melakukan penelitian sehingga alur penelitian dapat terstruktur. Gambar 1 merupakan metodologi penelitian ini. Tahap Penggalian Data merupakan tahap pertama dalam penelitian. Dalam tahap ini, peneliti akan melakukan pengumpulan data dan informasi yang terkait dengan penelitian. Di dalam tahap ini terdapat dua proses yang dilakukan, yaitu menyusun interview protocol dan menggali kondisi existing. Tahap kedua adalah Analisis Kondisi Existing dengan Kondisi Ekspektasi maupun Kondisi Ideal. Tahapan ini bertujuan untuk memetakan kondisi existing serta hasil kondisi kekinian yang telah terverifikasi dengan kondisi ideal berdasarkan kerangka kerja manajemen akses ITIL V3 dan ISO/IEC 27002:2005. Dari hasil pemetaan yang dilakukan akan didapatkan analisis proses pada kondisi existing terhadap kondisi ekspektasi atau kondisi ideal. Menurut manajemen akses ITIL V3, kondisi ideal dalam manajemen akses mencakup tujuh aktivitas yang perlu dilakukan, yaitu: request access, verification, providing rights, monitoring identity status, removing or restricting access, dan logging and tracking.

Dalam tahap ketiga, yaitu Tahap Analisis Kesenjangan, peneliti melakukan analisis kesenjangan dengan menggunakan hasil analisis proses pada kondisi existing terhadap kondisi ideal yang selanjutnya dilakukan analisis gap. Selain itu di dalam aktivitas ini dilakukan relevansi antara hasil proses yang mengalami kesenjangan dengan kontrol-kontrol yang ada di dalam ISO 27002:2005. Karena di dalam tabel analisis kesenjangan hanya menjelaskan kesenjangan antara proses dalam bisnis dengan proses Access Management. Sehingga relevansi antara hasil proses yang mengalami kesenjangan dengan kontrol-kontrol ISO 27002 digunakan untuk mendapatkan prosedur yang sesuai dan sebaiknya dilakukan.

Pada tahap keempat, peneliti menggunakan pedoman pembuatan SOP dalam melakukan pembuatan dokumen SOP. Peneliti menggunakan acuan Peraturan Menteri Pendayagunaan Aparatur Negara dan Reformasi Birokrasi Republik Indonesia Nomor 35 Tahun 2012 Tentang Pedoman Penyusunan Standar Operasional Prosedur Administrasi Pemerintahan dalam menyusun kriteria dan format SOP yang ada di dalam dokumen SOP [9]. Selain itu, dalam melakukan pembuatan dokumen SOP manajemen akses, peneliti menggunakan tabel analisis kesenjangan yang telah dilakukan sebelumnya. Adapun prosedur yang terdapat dalam dokumen SOP mencakup tujuh aktivitas dalam melakukan manajemen akses seperti yang telah dijelaskan dalam tahap analisis data. Setelah dokumen SOP manajemen akses tersusun, peneliti 
melakukan verifikasi dan validasi dokumen SOP manajemen akses sebagai bukti bahwa pembuatan dokumen SOP manajemen akses telah sesuai dengan objek penelitian.

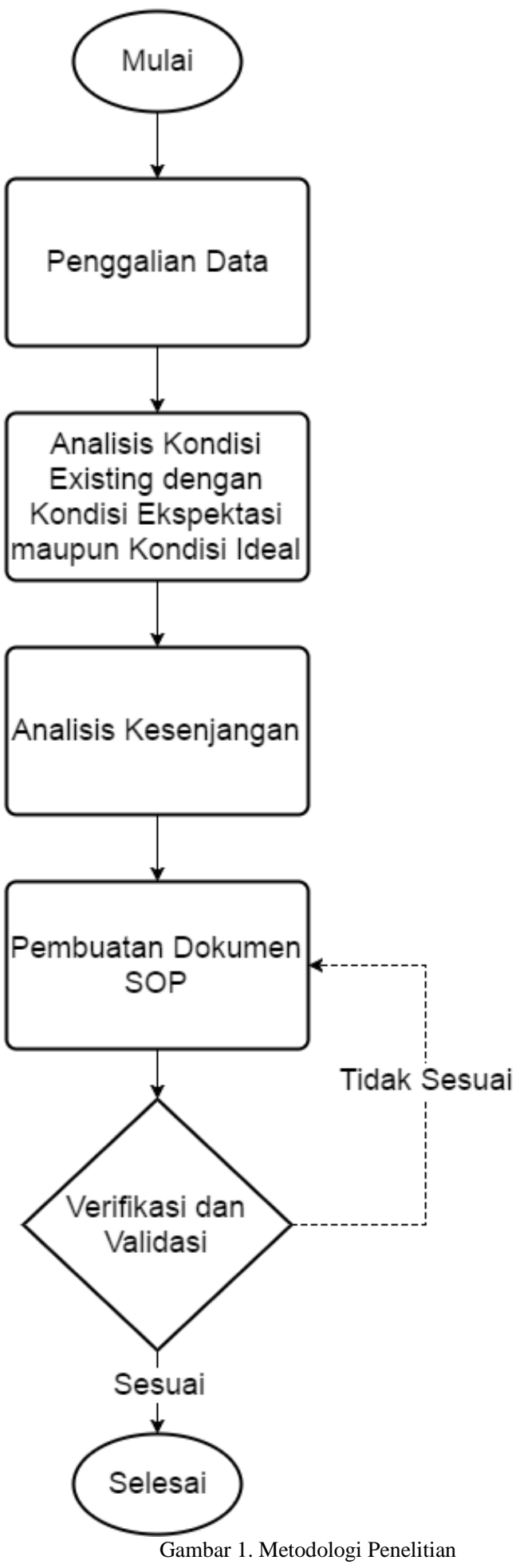




\section{Hasil dan Pembahasan}

\subsection{Penggalian Data Kondisi Existing Manajemen Akses}

Pada bagian ini, peneliti melakukan penggalian data terhadap kondisi kekinian dari manajemen akses yang dilakukan terhadap aplikasi E-Performance. Dalam melakukan penggalian data, penulis menggunakan teknik wawancara, observasi dan review dokumen terkait yang dibutuhkan dalam penelitian. Berikut adalah data dan informasi yang dibutuhkan dalam penelitian :

1) Peraturan /kebijakan pengelolaan akses, terkait dengan keamanan informasi berdasarkan standar acuan kontrol ISO 27002

2) Tentang aplikasi E-Performance, terkait dengan pengelolaan hak akses berdasarkan standar acuan manajemen akses ITIL, analisis kesenjangan dan kontrol ISO 27002.

3) Aktor aplikasi E-Performance, terkait dengan pengelolaan hak akses berdasarkan standar acuan manajemen akses ITIL

4) Role aplikasi E-Performance, terkait dengan pengelolaan hak akses berdasarkan standar acuan manajemen akses ITIL

5) Modul di dalam aplikasi E-Performance, terkait dengan pengelolaan hak akses berdasarkan standar acuan manajemen akses ITIL

6) Proses penggajian PNSD, terkait dengan keamanan informasi berdasarkan standar acuan kontrol ISO 27002

7) Proses penilaian kinerja PNSD, terkait dengan keamanan informasi berdasarkan standar acuan kontrol ISO 27002

8) Proses mutasi PNSD, terkait dengan pengelolaan hak akses berdasarkan standar cuan manajemen akses ITIL dan kontrol ISO 27002.

9) Alur pembuatan akses aplikasi E-Performance saat ini, terkait dengan aktivitas requesting access, verification dan providing rights pada manajemen akses ITIL

10) Alur pencatatan dan pelacakan akses aplikasi E-Performance saat ini, terkait dengan aktivitas logging and tracking access pada manajemen akses ITIL

11) Alur pengelolaan akses saat ini, terkait dengan aktivitas monitoring identity status dan removing or restricting rights pada manajemen akses ITIL

12)Pihak terkait selain aktor aplikasi E-Performance, terkait dengan keamanan informasi berdasarkan standar acuan kontrol ISO 27002

13) Alur pembuatan akses aplikasi E-Performance yang diharapkan, terkait dengan analisis kesenjangan antara kondisi kekinian dan kondisi ekspektasi maupun kondisi ideal standar acuan

14) Alur pencatatan dan pelacakan akses aplikasi E-Performance yang diharapkan, terkait dengan analisis kesenjangan antara kondisi kekinian dan kondisi ekspektasi maupun kondisi ideal standar acuan

15) Alur pengelolaan akses aplikasi E-Performance yang diharapkan, terkait dengan analisis kesenjangan antara kondisi kekinian dan kondisi ekspektasi maupun kondisi ideal standar acuan

Setelah mendapatkan data dan informasi yang dibutuhkan, selanjutnya penulis melakukan analisis kondisi kekinian dengan kondisi ekspektasi yang diharapkan oleh Bagian Bina Program maupun Kondisi Ideal standar acuan.

\subsection{Analisis Kondisi Existing dengan Kondisi Ekspektasi maupun Kondisi Ideal Manajemen Akses}

Pada bagian ini, peneliti melakukan analisis kondisi kekinian dengan kondisi ekspektasi yang diharapkan oleh Bagian Bina Program maupun Kondisi Ideal standar acuan. Dalam melakukan analisis, penulis mengacu pada 4 aspek penting dalam mendesain sebuah layanan TI berdasarkan tahapan service design ITIL V3, yaitu People, Processes, Product dan Partners [10]. Dalam penelitan, penulis menggunakan aspek people dan processes karena berdasarkan standar, sebuah organisasi dapat merasakan keuntungan dari penggunaan ITIL ketika terdapat kesesuaian dan kejelasan terhadap proses dan pihak yang terkait 
dengan proses. Sedangkan di dalam studi kasus yang berfokus pada manajemen akses, kesesuaian proses dan sumber daya terkait menjadi hal yang penting. Oleh karena itu peneliti menggunakan dua aspek dari empat aspek yang digunakan. Sedangkan terkait kondisi ideal manajemen akses, penulis menggunakan acuan ITIL V3 Access Management. Tabel 1 merangkum kondisi kekinian dan kondisi ekspektasi maupun kondisi ideal berdasarkan aspek yang digunakan dan aktivitas pada access management ITIL V3.

Tabel 1. Kondisi Kekinian dan Kondisi Ekspektasi

\begin{tabular}{|c|c|c|}
\hline Aspek & Aktivitas & Kondisi Kekinian \\
\hline \multirow[t]{4}{*}{ Proses } & Requesting Access & User Baru \\
\hline & & $\begin{array}{l}\text { PNSD baru yang terdaftar dicatat oleh BKD } \\
\text { dan admin SKPD, lalu admin SKPD terkait } \\
\text { menyusun list permintaan pengguna baru } \\
\text { yang diserahkan melalui email/surat kepada } \\
\text { Super Admin Bina Program. BKD juga } \\
\text { menyerahkan list PNSD baru kepada Super } \\
\text { Admin Bina Program melalui email/surat } \\
\text { untuk dicek kesesuaiannya. Jika telah } \\
\text { sesuai maka Super Admin akan membuka } \\
\text { akses login admin SKPD untuk membuat } \\
\text { pengguna baru. }\end{array}$ \\
\hline & & User Lama \\
\hline & & $\begin{array}{l}\text { PNSD yang telah terdaftar memberikan } \\
\text { Surat Keputusan kepada admin SKPD } \\
\text { melalui email/surat untuk merubah hak } \\
\text { akses maupun status pengguna. Apabila SK } \\
\text { sesuai dengan permintaan perubahan maka } \\
\text { admin SKPD akan melakukan perubahan }\end{array}$ \\
\hline
\end{tabular}

Verification

Providing rights
Verifikasi dilakukan dengan melakukan pencocokan data antara SK terkait dengan permintaan pengguna. Admin SKPD juga berperan sebagai verifikator permintaan. Selain itu admin SKPD juga melakukan pengecekan basis data pengguna aplikasi EPerformance

Pemberian hak akses aplikasi EPerformance dilakukan oleh admin SKPD terkait kepada pengguna baru/lama dengan menggunakan email/surat.
User Baru :

PNSD baru yang terdaftar dicatat oleh BKD dan admin SKPD. PNSD baru melakukan permintaan akses baru yang selanjutnya akan diterima oleh Service Desk. Service Desk akan mencatat permintaan dan meneruskan nya kepada admin SKPD. Admin SKPD terkait menerima list permintaan pengguna baru dan diserahkan melalui email/surat kepada Super Admin Bina Program. BKD juga menyerahkan list PNSD baru kepada Super Admin Bina Program melalui email/surat untuk dicek kesesuaiannya. Apabila telah sesuai maka Super Admin akan membuka akses login admin SKPD untuk membuat pengguna baru dan melakukan perekaman permintaan akses baru.

User Lama :

PNSD yang telah terdaftar memberikan Surat Keputusan kepada admin SKPD melalui email/surat untuk merubah hak akses maupun status pengguna. Apabila SK sesuai dengan permintaan perubahan maka admin SKPD akan melakukan perubahan. Admin SKPD mencatat permintaan perubahan akses.

Verifikasi dilakukan dengan melakukan pencocokan data antara SK terkait dengan permintaan pengguna. Admin SKPD juga berperan sebagai verifikator permintaan. Sedangkan Super Admin maupun Tim Manajemen Kinerja berperan sebagai validator dari akses yang dibuat oleh admin SKPD. Selain itu admin SKPD juga melakukan pengecekan basis data pengguna aplikasi E-Performance

Pemberian hak akses aplikasi $E$ Performance dilakukan oleh admin SKPD terkait kepada pengguna baru/lama dengan menggunakan email/surat beserta rincian kebijakan serta modul yang dapat diakses maupun yang tidak dapat diakses. Selain itu adanya perekaman pemberian akses 


\begin{tabular}{|c|c|c|c|}
\hline Aspek & Aktivitas & Kondisi Kekinian & Kondisi Ekspektasi \\
\hline & & & yang telah dilakukan. \\
\hline & $\begin{array}{l}\text { Monitoring identity } \\
\text { status }\end{array}$ & $\begin{array}{l}\text { Pemantauan status identitas dilakukan } \\
\text { bersamaan dengan proses pencatatan dan } \\
\text { pelacakan akses. }\end{array}$ & $\begin{array}{l}\text { Adanya pemantauan status identitas } \\
\text { akses secara berkala, terutama pada } \\
\text { proses pengisian tes perilaku kerja } \\
\text { untuk tipe aktor tertentu. }\end{array}$ \\
\hline & $\begin{array}{l}\text { Removing or } \\
\text { restricting rights }\end{array}$ & $\begin{array}{l}\text { Admin SKPD maupun Super Admin } \\
\text { menggunakan SK pengguna terkait sebagai } \\
\text { dasar dalam melakukan penghapusan } \\
\text { maupun pembatasan akses. Namun data } \\
\text { PNSD yang telah dihapus tidak hilang } \\
\text { secara permanen. }\end{array}$ & $\begin{array}{l}\text { Admin SKPD maupun Super Admin } \\
\text { menggunakan SK pengguna terkait } \\
\text { sebagai dasar dalam melakukan } \\
\text { penghapusan maupun pembatasan } \\
\text { akses. Namun data PNSD yang telah } \\
\text { dihapus tidak hilang secara permanen. } \\
\text { Selain itu, adanya perekaman } \\
\text { penghapusan akses dan verifikasi serta } \\
\text { validasi oleh Tim Manajemen Kinerja. }\end{array}$ \\
\hline & $\begin{array}{l}\text { Logging and tracking } \\
\text { accesss }\end{array}$ & $\begin{array}{l}\text { Secara otomatis sistem akan melakukan } \\
\text { pencatatan log akses sistem oleh pengguna. } \\
\text { Selain itu proses pencatatan dan pelacakan } \\
\text { dilakukan ketika dibutuhkan. }\end{array}$ & $\begin{array}{l}\text { Sistem akan melakukan pencatatan } \\
\text { tidak hanya log akses sistem saja, } \\
\text { namun terdapat log histori akses modul. } \\
\text { Dari penggunaan log akses dapat } \\
\text { diketahui pemetaan akses pengguna } \\
\text { aplikasi. Serta terdapat alur dalam } \\
\text { melakukan pelaporan permasalahan } \\
\text { akses }\end{array}$ \\
\hline
\end{tabular}

Dalam aspek people, terdapat 2 tipe aktor dan 6 tipe role dari aplikasi. Adapun 2 tipe aktor adalah Pejabat Struktural dan Pejabat Non Struktural, sedangkan 6 tipe role adalah Super Admin Bina Program, Admin SKPD, Pejabat Level 1, Pejabat Level 2, Pejabat Level 3 dan Pegawai Level 4. Setelah melakukan analisis kondisi kekinian dan kondisi ekspektasi maupun kondisi ideal, penulis melakukan analisis kesenjangan.

\subsection{Analisis Kesenjangan Kondisi Existing dengan Kondisi Ekspektasi maupun Kondisi Ideal Manajemen Akses}

Pada bagian ini, penulis melakukan analisis kesenjangan untuk mengetahui kelemahan atau kekurangan dari kondisi kekinian terhadap kondisi ekspektasi maupun kondisi ideal berdasarkan standar acuan. Analisis kesenjangan juga dapat mengidentifikasi proses-proses yang kurang efektif sehingga dapat mengurangi kesenjangan agar tercapainya kondisi yang diharapkan [11]. Caranya adalah dengan membandingkan kondisi kekinian dengan kondisi ekspektasi maupun kondisi ideal. Dari hasil kesenjangan yang ada akan didapatkan usulan-usulan yang dapat digunakan sebagai input dalam membuat dokumen Standard Operating Procedure Manajemen Akses Aplikasi E-Performance. Selain itu dengan adanya analisis kesenjangan akan didapatkan perubahan, dampak dan solusi atas kesenjangan yang terjadi. Tabel 2 memaparkan mengenai analisis kesenjangan.

Tabel 2. Analisis Kesenjangan

\begin{tabular}{llll}
\hline Aspek & Aktivitas & \multicolumn{1}{c}{ Kesenjangan Proses } & \multicolumn{1}{c}{ Perubahan } \\
\hline Proses & Requesting Access & $\begin{array}{l}\text { Diperlukan perekaman terhadap } \\
\text { permintaan akses baru dan } \\
\text { permintaan terhadap perubahan } \\
\text { akses }\end{array}$ & $\begin{array}{l}\text { Terdapat kebutuhan dalam pendokumentasian } \\
\text { permintaan akses dan perubahan struktur } \\
\text { organisasi }\end{array}$ \\
\hline
\end{tabular}




\begin{tabular}{|c|c|c|c|}
\hline Aspek & Aktivitas & Kesenjangan Proses & Perubahan \\
\hline & Verification & $\begin{array}{l}\text { Adanya validator akses sebagai } \\
\text { bukti akses telah terverifikasi } \\
\text { dan dapat berupa tanda tangan } \\
\text { validator }\end{array}$ & $\begin{array}{l}\text { Terdapat kebutuhan dalam pendokumentasian } \\
\text { verifikasi }\end{array}$ \\
\hline & Providing rights & $\begin{array}{l}\text { Diperlukan pemberian rincian } \\
\text { kebijakan serta modul kepada } \\
\text { pegawai dan terdapat perekaman } \\
\text { pemberian akses yang telah } \\
\text { dilakukan }\end{array}$ & $\begin{array}{l}\text { Terdapat kebutuhan dalam pendokumentasian } \\
\text { pemberian akses }\end{array}$ \\
\hline & $\begin{array}{l}\text { Monitoring identity } \\
\text { status }\end{array}$ & $\begin{array}{l}\text { Diperlukan pemantauan status } \\
\text { identitias akses secara berkala } \\
\text { dan saat proses pengisian tes } \\
\text { perilaku kerja }\end{array}$ & $\begin{array}{l}\text { Terdapat kebutuhan dalam pendokumentasi } \\
\text { pemantauan identitas akses }\end{array}$ \\
\hline & $\begin{array}{l}\text { Removing or } \\
\text { restricting rights }\end{array}$ & $\begin{array}{l}\text { Adanya perekaman penghapusan } \\
\text { akses dan verifikasi serta validasi }\end{array}$ & $\begin{array}{l}\text { Terdapat kebutuhan dalam pendokumentasi } \\
\text { penghapusan maupun pembatasan akses }\end{array}$ \\
\hline & $\begin{array}{l}\text { Logging and tracking } \\
\text { accesss }\end{array}$ & $\begin{array}{l}\text { Diperlukan pencatatan terhadap } \\
\text { log histori akses modul dan alur } \\
\text { pelaporan permasalahan akses }\end{array}$ & $\begin{array}{l}\text { Terdapat kebutuhan dalam pendokumentasi } \\
\text { pencatatan dan pelacakan akses serta perubahan } \\
\text { struktur organisasi }\end{array}$ \\
\hline
\end{tabular}

Dalam aspek People tidak terdapat kesenjangan karena kebutuhan akan pengelolaan akses dengan sumber daya manusia yang dimiliki saat ini telah tercukupi. Hal ini berdasarkan standar acuan proses Change Management pada service transition ITIL V3, yang menyatakan bahwa jumlah dan ketersediaan sumber daya manusia yang dibutuhkan bergantung pada perubahan layanan yang terjadi, dan perubahan layanan akan semakin efektif apabila dikerjakan oleh SDM dalam jumlah sedikit [12]. Selain analisis kesenjangan, akan diidentifikasi pula dampak dan perubahan dari adanya identifikasi perubahan pada analisis kesenjangan. Identifikasi dampak diperoleh dari hasil identifikasi perubahan pada analisis kesenjangan. Identifikasi dampak diperlukan untuk mengetahui akibat dari perpindahan kondisi saat ini ke kondisi ekspektasi atau kondisi ideal berdasarkan standar acuan. Selanjutnya akan diidentifikasi solusi dari dampak perubahan yang terjadi, sehingga akan didapatkan manfaat dari perubahan yang terjadi. Adapun hasil identifikasi dampak dan solusi dari analisis kesenjangan dapat dilihat pada Tabel 3.

Tabel 3. Identifikasi Dampak dan Solusi

\begin{tabular}{clll}
\hline Aspek & \multicolumn{1}{c}{ Aktivitas } & \multicolumn{1}{c}{ Dampak atas Proses } & \multicolumn{1}{c}{ Solusi } \\
\hline Proses & Requesting Access & $\begin{array}{l}\text { Adanya penyusunan prosedur baru yang } \\
\text { jelas agar dapat meningkatkan kinerja dan } \\
\text { efisiensi organisasi dalam menyelesaikan } \\
\text { permintaan akses }\end{array}$ & $\begin{array}{l}\text { Pembuatan prosedur baru terkait } \\
\text { permintaan akses untuk semua } \\
\text { struktur pengguna aplikasi }\end{array}$ \\
& $\begin{array}{l}\text { Adanya aktivitas dalam mengambil } \\
\text { formulir permintaan akses, mengisikan } \\
\text { formulir permintaan akses dan } \\
\text { mengembalikan formulir permintaan akses }\end{array}$ & $\begin{array}{l}\text { Pembuatan formulir permintaan } \\
\text { akses sesuai dengan konten } \\
\text { informasi yang diperlukan serta } \\
\text { terdapat bukti tandatangan } \\
\text { penanggung jawab }\end{array}$ \\
\hline
\end{tabular}




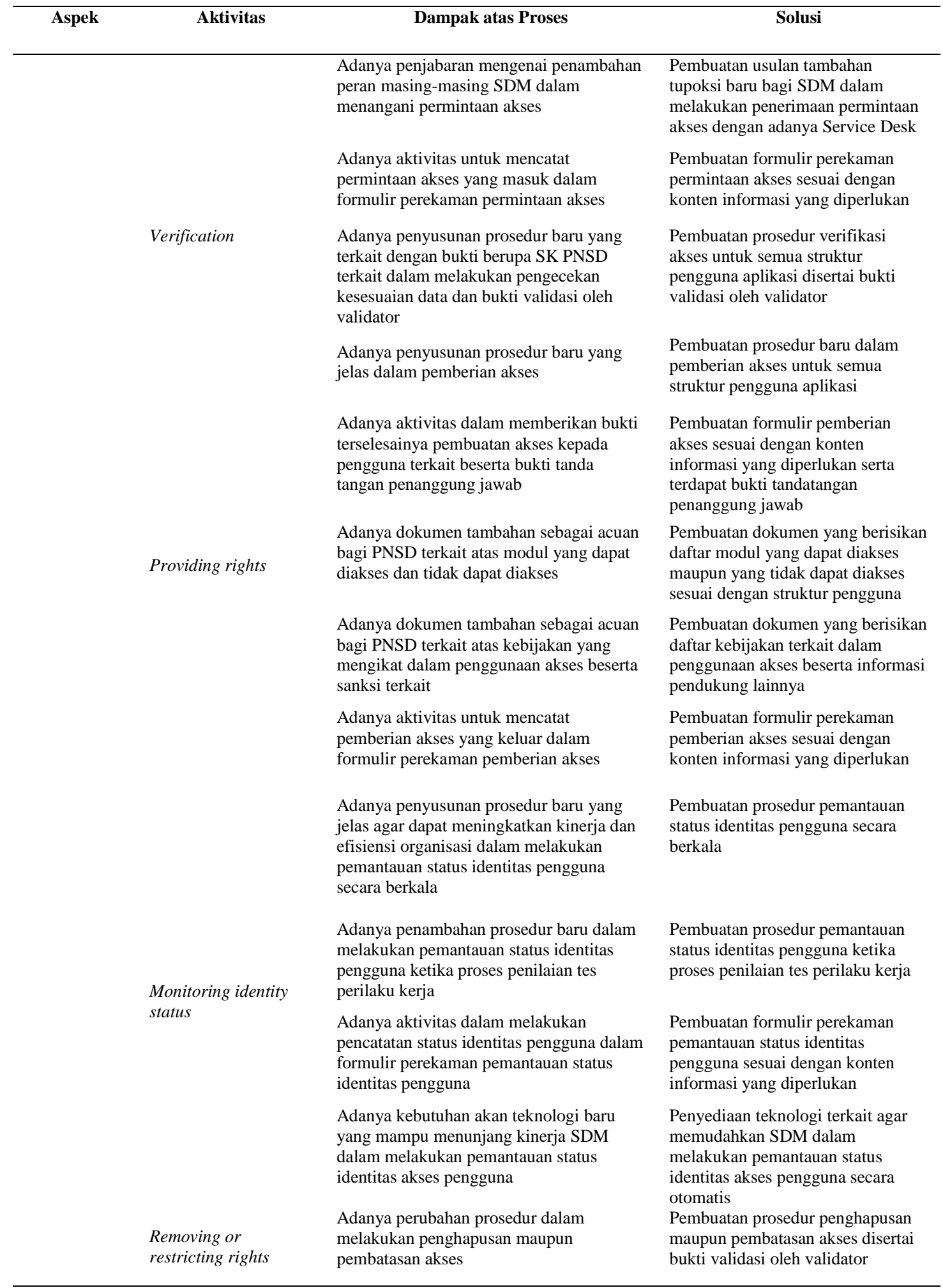




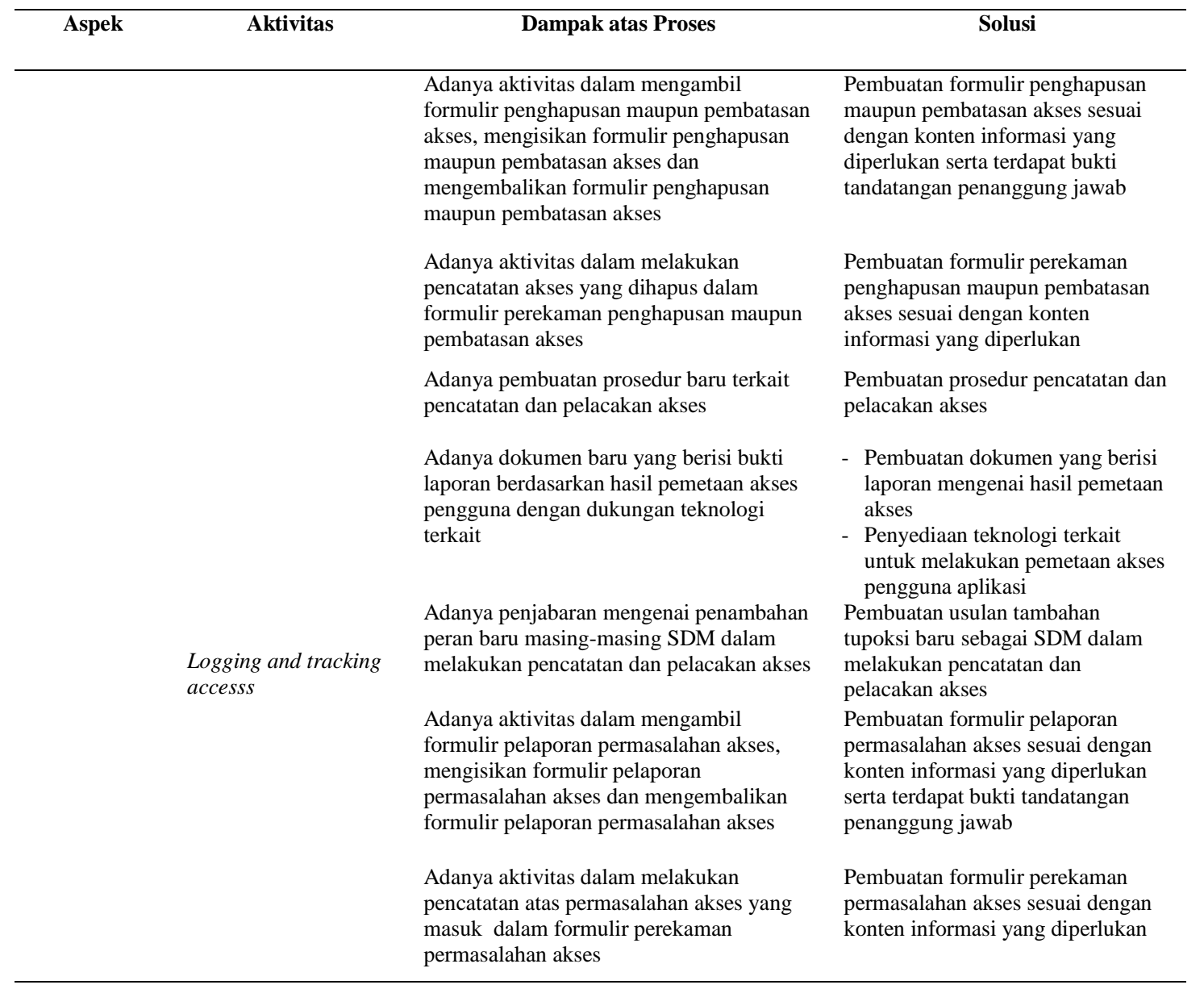

\subsection{Pembuatan Dokumen SOP Manajemen Akses}

Pembuatan Standard Operating Procedure disusun berdasarkan hasil analisis kesenjangan yang telah dilakukan. Pembuatan SOP mengacu pada Peraturan Menteri Pendayagunaan Aparatur Negara dan Reformasi Birokrasi Republik Indonesia Nomor 35 Tahun 2012 Tentang Pedoman Penyusunan Standar Operasional Prosedur Administrasi Pemerintahan. Dalam penyusunan SOP, penulis menggunakan ISO 27002 sebagai kontrol yang digunakan dalam prosedur. Penentuan kontrol ISO/IEC 27002 yang digunakan dalam prosedur telah disesuaikan dengan relevansi antara aktivitas manajemen akses serta kondisi existing maupun kondisi ideal manajemen akses [13].

Tabel 4. Pemetaan Kontrol pada Prosedur

\begin{tabular}{lccc}
\hline $\begin{array}{c}\text { Aktivitas Access } \\
\text { Management }\end{array}$ & $\begin{array}{c}\text { Kontrol ISO } \\
\mathbf{2 7 0 0 2}\end{array}$ & Deskripsi Kontrol & Aktivitas pada Prosedur \\
\hline Requesting Access & $\begin{array}{c}\text { 11.2.1 User } \\
\text { registration }\end{array}$ & $\begin{array}{c}\text { - ID pengguna yang bersifat } \\
\text { unique }\end{array}$ & $\begin{array}{c}\text { - Membuat akun email pegawai dengan domain } \\
\text { surabaya.go.id }\end{array}$ \\
& $\begin{array}{c}\text { - Memastikan pengguna } \\
\text { memiliki otorisasi akses }\end{array}$ & $\begin{array}{c}\text { - Membuat akun aplikasi E-Performance } \\
\text { dengan username berdasarkan NIP Pegawai }\end{array}$ \\
\hline
\end{tabular}




\begin{tabular}{|c|c|c|c|}
\hline $\begin{array}{l}\text { Aktivitas Access } \\
\text { Management }\end{array}$ & $\begin{array}{l}\text { Kontrol ISO } \\
27002\end{array}$ & Deskripsi Kontrol & Aktivitas pada Prosedur \\
\hline & & & dan password awal secara acak \\
\hline & & $\begin{array}{l}\text { - Pencatatan pengguna yang } \\
\text { melakukan permintaan } \\
\text { akses }\end{array}$ & $\begin{array}{l}\text { - Melakukan pencatatan pada formulir } \\
\text { perekaman permintaan akses }\end{array}$ \\
\hline \multirow[t]{5}{*}{ Verification } & $\begin{array}{l}8.1 .1 \text { Roles and } \\
\text { responsibilities }\end{array}$ & $\begin{array}{l}\text { - Melakukan pengecekan } \\
\text { kesesuaian akses terhadap } \\
\text { masing-masing aktor }\end{array}$ & $\begin{array}{l}\text { - Melakukan peninjauan terhadap kesesuaian } \\
\text { akses masing-masing aktor dan rolenya dari } \\
\text { daftar acuan role }\end{array}$ \\
\hline & & $\begin{array}{l}\text { - Melindungi asset } \\
\text { informasi dari akses yang } \\
\text { tidak terotorisasi }\end{array}$ & $\begin{array}{l}\text { - Memastikan bahwa role dan akses yang } \\
\text { dimiliki pegawai telah sesuai }\end{array}$ \\
\hline & $\begin{array}{l}\text { 11.3.1 } \\
\text { Password use }\end{array}$ & $\begin{array}{l}\text { - Menjamin kerahasiaan } \\
\text { password }\end{array}$ & $\begin{array}{l}\text { - Memastikan password pegawai telah } \\
\text { terenkripsi dan tercatat dalam database }\end{array}$ \\
\hline & $\begin{array}{l}\text { 11.5.2 User } \\
\text { identification } \\
\text { and } \\
\text { authentication }\end{array}$ & $\begin{array}{l}\text { - Melakukan pengecekan ID } \\
\text { pengguna dan status } \\
\text { pengguna }\end{array}$ & $\begin{array}{l}\text { - Melihat kesesuaian antara SK Pegawai } \\
\text { dengan akses yang diberikan kepada pegawai } \\
\text { dengan melihat database identitas pegawai }\end{array}$ \\
\hline & & $\begin{array}{l}\text { - Melakukan verifikasi dan } \\
\text { otentikasi ID pengguna }\end{array}$ & $\begin{array}{l}\text { - Mengirimkan link verifikasi kepada email } \\
\text { pegawai sebagai bukti bahwa akses yang akan } \\
\text { diberikan sesuai dengan identitas pegawai }\end{array}$ \\
\hline \multirow[t]{6}{*}{ Providing rights } & $\begin{array}{l}6.1 .5 \\
\text { Confidentiality } \\
\text { agreements }\end{array}$ & $\begin{array}{l}\text { - Memastikan pengguna } \\
\text { menyetujui perjanjian } \\
\text { kerahasiaan informasi }\end{array}$ & $\begin{array}{l}\text { - Memberikan daftar kebijakan terkait } \\
\text { manajemen akses kepada masing-masing } \\
\text { pegawai beserta sanksi terkait }\end{array}$ \\
\hline & $\begin{array}{l}\text { 11.2.2 Privilege } \\
\text { management }\end{array}$ & $\begin{array}{l}\text { - Memastikan pengguna } \\
\text { memahami hak akses yang } \\
\text { diperolehnya }\end{array}$ & $\begin{array}{l}\text { - Memberikan daftar modul yang dapat diakses } \\
\text { serta yang tidak dapat diakses kepada masing- } \\
\text { masing pegawai }\end{array}$ \\
\hline & & & $\begin{array}{l}\text { - Menekan link verifikasi yang diberikan } \\
\text { kepada pegawai }\end{array}$ \\
\hline & & $\begin{array}{l}\text { - Pencatatan pengguna yang } \\
\text { telah diberikan akses }\end{array}$ & $\begin{array}{l}\text { - Melakukan pencatatan pada formulir } \\
\text { perekaman pemberian akses }\end{array}$ \\
\hline & $\begin{array}{l}\text { 11.2.3 User } \\
\text { password } \\
\text { management }\end{array}$ & $\begin{array}{l}\text { - Memastikan pengguna } \\
\text { memahami aturan } \\
\text { mengenai manajemen } \\
\text { password }\end{array}$ & $\begin{array}{l}\text { - Memberikan daftar acuan kepada pegawai } \\
\text { mengenai kebijakan dalam penggantian } \\
\text { password dan konten password yang sesuai } \\
\text { dengan standar acuan }\end{array}$ \\
\hline & $\begin{array}{l}\text { 11.4.1 Policy on } \\
\text { use of network } \\
\text { service }\end{array}$ & $\begin{array}{l}\text { - Memastikan pengguna } \\
\text { memahami kebijakan } \\
\text { terkait layanan akses }\end{array}$ & $\begin{array}{l}\text { - Memberikan daftar acuan mengenai layanan } \\
\text { akses yang dapat diakses dari jaringan umum } \\
\text { maupun khusus }\end{array}$ \\
\hline Monitoring identity status & $\begin{array}{l}\text { 11.1.1 Access } \\
\text { control policy }\end{array}$ & $\begin{array}{l}\text { - Melakukan pengecekan } \\
\text { kesesuaian akses pengguna } \\
\text { berdasarkan kebijakan } \\
\text { kontrol akses }\end{array}$ & $\begin{array}{l}\text { - Memastikan akses pegawai sesuai dengan } \\
\text { kontrol-kontrol dalam acuan }\end{array}$ \\
\hline
\end{tabular}




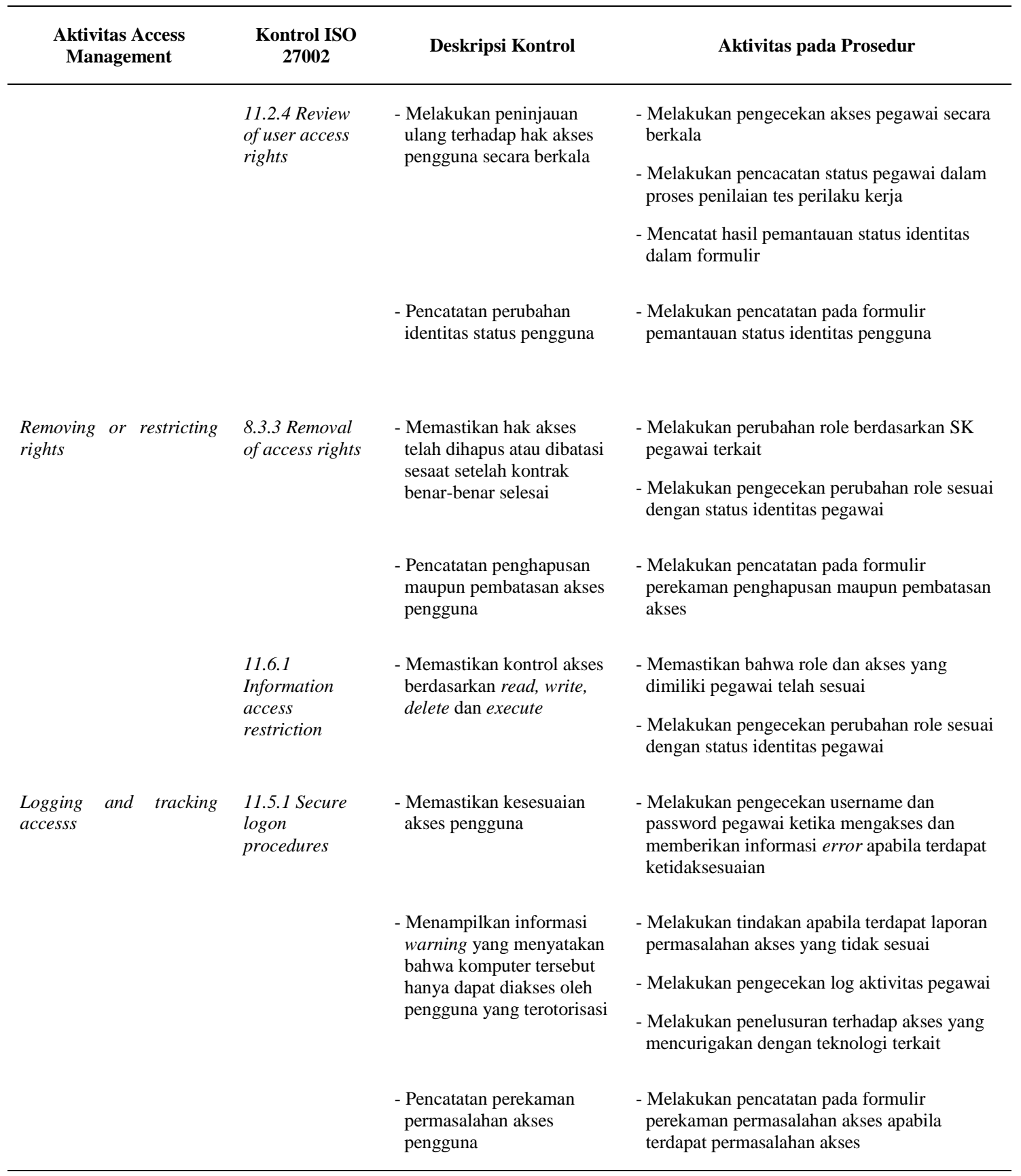

Adapun dalam penyusunan format SOP, didasarkan pada tujuan dari pembuatan SOP dan tidak terdapat format baku dalam penyusunan format SOP [14]. Sehingga apabila terdapat perbedaan tujuan pembuatan SOP, maka format SOP juga akan berbeda. Dalam melakukan pembuatan dokumen SOP, penulis memetakan kontrol yang ada di dalam ISO/IEC 27002:2005 ke dalam aktivitas yang tertera dalam prosedur seperti disajikan dalam Tabel 4. 
Setelah melakukan pemetaan kontrol, penulis melakukan penyusunan struktur dan konten SOP sesuai dengan acuan pembuatan SOP. Tabel 5 mendaftar prosedur dan formulir yang terdapat dalam SOP Manajemen Akses aplikasi E-Performance.

Tabel 5. Prosedur dan Formulir Dokumen SOP

\begin{tabular}{|c|c|c|c|}
\hline Nomor SOP & Nama SOP & Nomor Formulir & Nama Formulir \\
\hline \multirow[t]{2}{*}{ SOP-Akses-001 } & \multirow[t]{2}{*}{ SOP Permintaan Akses } & FRM-Akses-001 & Formulir Permintaan Akses \\
\hline & & FRM-Akses-002 & Formulir Perekaman Permintaan Akses \\
\hline \multirow[t]{2}{*}{ SOP-Akses-002 } & \multirow{2}{*}{$\begin{array}{l}\text { SOP Verifikasi } \\
\text { Pemberian Akses }\end{array}$} & FRM-Akses-003 & Formulir Pemberian Akses \\
\hline & & FRM-Akses-004 & Formulir Perekaman Pemberian Akses \\
\hline SOP-Akses-003 & $\begin{array}{l}\text { SOP Pemantauan } \\
\text { Identitas }\end{array}$ & FRM-Akses-005 & $\begin{array}{l}\text { Formulir Perekaman Pemantauan Status } \\
\text { Identitas Pengguna }\end{array}$ \\
\hline SOP-Akses-004 & $\begin{array}{l}\text { SOP Pemantauan Akses Tes } \\
\text { Perilaku Kerja }\end{array}$ & FRM-Akses-006 & $\begin{array}{l}\text { Formulir Perekaman Pemantauan Penilaian } \\
\text { Tes Perilaku Kerja }\end{array}$ \\
\hline \multirow[t]{2}{*}{ SOP-Akses-005 } & \multirow[t]{2}{*}{$\begin{array}{l}\text { SOP Penghapusan } \\
\text { Pembatasan Akses }\end{array}$} & FRM-Akses-007 & $\begin{array}{l}\text { Formulir Penghapusan atau Pembatasan } \\
\text { Akses }\end{array}$ \\
\hline & & FRM-Akses-008 & $\begin{array}{l}\text { Formulir Perekaman Penghapusan atau } \\
\text { Pembatasan Akses }\end{array}$ \\
\hline \multirow[t]{4}{*}{ SOP-Akses-006 } & \multirow{4}{*}{$\begin{array}{l}\text { SOP Pencatatan } \\
\text { Pelacakan Akses }\end{array}$} & FRM-Akses-009 & Formulir Pelaporan Permasalahan Akses \\
\hline & & FRM-Akses-010 & Formulir Perekaman Permasalahan Akses \\
\hline & & FRM-Akses-011 & Formulir Laporan Pencatatan Akses \\
\hline & & FRM-Akses-012 & $\begin{array}{l}\text { Formulir Laporan Tindakan Keamanan } \\
\text { Informasi }\end{array}$ \\
\hline
\end{tabular}

\section{Kesimpulan}

\subsection{Simpulan}

Berdasarkan hasil penggalian data, diketahui bahwa terdapat enam role dan dua tipe aktor. Aktor tersebut adalah Pejabat Struktural dan Pejabat Non Struktural. Pejabat Struktural dapat memiliki jenis role Pejabat Level 1, Pejabat Level 2, Pejabat Level 3 maupun Admin SKPD. Sedangkan Pejabat Non Struktural dapat memiliki jenis role Super Admin Bina Program, Admin SKPD dan Pegawai Level 4. Selain itu, dari hasil analisis kesenjangan yang telah dilakukan, didapatkan satu tambahan aktivitas dalam manajemen akses, yaitu terkait pemantauan status saat tes perilaku kerja berlangsung. Dari hasil analisis kesenjangan didapatkan pula adanya perubahan struktur dan peran SDM dalam pengelolaan akses, serta penambahan kebijakan terkait pengelolaan manajemen akses. Di dalam SOP, terdapat beberapa prosedur dan sub prosedur. Dalam menentukan sub prosedur, didasarkan pada perbedaan aktivitas dalam prosedur dan keterlibatan aktor dalam prosedur. Sedangkan dalam menentukan prosedur, didasarkan pada aktivitas manajemen akses sesuai dengan standar acuan. Hasil penelitian berupa dokumen SOP manajemen akses yang telah disesuaikan dengan standar acuan. Di dalam dokumen SOP juga terdapat dua belas formulir, daftar kebijakan manajemen password, daftar acuan modul dan daftar acuan role yang membantu terlaksananya prosedur manajemen akses. Setelah dokumen SOP selesai disusun, dilakukanlah verifikasi dan validasi SOP untuk memastikan kesesuaian informasi maupun aktivitas yang ada di dalam prosedur, formulir, dan daftar acuan terkait. Setelah dilakukan perbaikan dari hasil verifikasi dan validasi, dokumen 
SOP dapat digunakan dalam penerapan manajemen akses aplikasi E-Performance oleh Bagian Bina Program Kota Surabaya.

\subsection{Saran}

Saran yang dapat disampaikan untuk penelitian selanjutnya adalah:

1) Dalam penelitian ini, dilakukan pembatasan terhadap pengidentifikasian kontrol yang terdapat dalam ISO/IEC 27002:2005 sebelum dilakukan analisis kesenjangan. Sehingga yang terjadi adalah terdapat kontrol diluar batasan yang dapat digunakan dalam penelitian. Dalam penelitian selanjutnya,dapat dilakukan pembatasan pengidentifikasian kontrol setelah dilakukan analisis kesenjangan untuk memastikan kontrol sesuai dengan kebutuhan dalam penelitian.

2) Penelitian ini tidak melakukan pemantauan terhadap penggunaan SOP di dalam aktivitas sehari-hari. Untuk penelitian selanjutnya dapat dilakukan penilaian kinerja dan evaluasi terhadap penerapan SOP yang nantinya dapat mengetahui keefektifan SDM terkait dalam menunjang penerapan SOP.

\section{Daftar Pustaka}

[1] Walikota Surabaya, 2013. Peraturan Walikota Surabaya Nomor 5 Tahun 2013 Tentang Pedoman Pemanfaatan Teknologi Informasi Dan Komunikasi Dalam Penyelenggaraan Pemerintahan Daerah. Surabaya.

[2] Bina Program Kota Surabaya, 2015. Dokumen Profil Bagian Bina Program Kota Surabaya. Surabaya.

[3] UCISA, 2002. ITIL - A Guide to Access Management. University of Oxford.

[4] Pemerintah Kota Surabaya, 2015. E-Performance [Online] .Available at: https://eperformance.surabaya.go.id/2015/. [Accessed 25 January 2016]

[5] Badan Kepegawaian Daerah Kota Surabaya, 2015. Kondisi Umum Kepegawaian [Online] .Available at: http://bkd.surabaya.go.id/content.php?page=10. [Accessed 16 January 2016]

[6] Carrtlidge, Hanna dan Rudd, C., 2007. An Introductory Overview of ITIL® V3, Version 1.0. UK: The UK Chapter of the itSMF.

[7] Badan Kepegawaian Daerah Kota Semarang, 2012. Pedoman Penyusunan Administrasi Pemerintahan. Semarang.

[8] Griffin, R. W., 2004. Manajemen. Jakarta: Erlangga.

[9] International Standard Organization (ISO), 2005. ISO/IEC 27002 Information technology — Security techniques — Code of practice for information security controls, First Edition. Switzerland.

[10] Office of Government Commerce (OCG), 2007. ITIL Version 3 Service Design. United Kingdom: The Stationery Office.

[11] Murray, J., 2000. A GAP Analysis Process To Improve IT Management. 1 (4), pp.35.

[12] Office of Government Commerce (OCG), 2007. ITIL Version 3 Service Transition. United Kingdom: The Stationery Office.

[13] IT Governance Institute, 2008. Aligning CobiT®4.1, ITIL ®V3 and ISO/IEC 27002 for Business Benefit. United States.

[14] Budihardjo, M., 2014. Panduan Praktis Menyusun SOP. Yogyakarta: Gadjah Mada University Press. 
Wildan Radista Wicaksana et al. / Jurnal Sisfo Vol.06 No.01 (2016) 105-120

Halaman ini sengaja dikosongkan 